\title{
POBREZA Y BENEFICENCIA EN EL CÁDIZ DEL SIGLO XVIII ${ }^{1}$
}

\author{
Arturo Morgado García \\ Universidad de Cádiz
}

\section{$\underline{\text { RESUMEN }}$}

Análisis de las características de la pobreza y de la situación de la beneficencia en el Cádiz del siglo XVIII.

Palabras clave: España, siglo XVIII. Historia Social. Pobreza. Beneficencia.

\section{$\underline{A B S T R A C T}$}

Analisys of the characters of the poverty and the situation of Welfare in Cadix at XVIII' ${ }^{\text {th }}$ century.

Keywords: Spain, XVIII ${ }^{\text {ih }}$ century. Social history. Poverty. Welfare

\section{UNA CARACTERIZACION DE LA MISERIA}

Durante el Antiguo Régimen la pobreza constituye una realidad cuyos perfiles resultan bastante difusos, por cuanto la misma no nos aparece ni mucho menos circunscrita a un sector concreto, más o menos extenso, de la población, antes al contrario, era una amenaza continuamente presente, por cuanto una situación aparentemente desahogada podía fácilmente derivar hacia la miseria ante la muerte, la enfermedad, la crisis de subsistencias, o una mala coyuntura económica, y ello lo puso muy bien de relieve Stuart Woolf ${ }^{2}$, con su distinción entre pobres estructurales, entendiendo por tales un sector de la población sumido permanentemente en la precariedad, y pobres coyunturales, o aquéllos a los cuales la fatalidad, un factor imprevisto, o, simplemente, la mala suerte, les hacía caer en un proceso de pauperización.

Es dificil, en línea con lo anteriormente expuesto, calcular cuantos pobres había en el Cádiz del siglo XVIII, y las propias autoridades no estaban muy segu-

\footnotetext{
' Conferencia pronunciada en el marco del ciclo Instituciones benéficas en Cádiz durante los siglos XVIII-XIX-XX (Universidad de Cádiz, mayo de 2001).

2 WOOLF, Stuart, Los pobres en la Europa Moderna, Barcelona, Crítica, 1989, p.17.
} 
ras de su número, siendo muy reveladora la respuesta que los encargados de efectuar las averiguaciones conducentes a la confección del Catastro de Ensenada realizaron a la pregunta 36 del mismo, a saber, "Cuantos pobres de solemnidad habrá en la Población. Ha sido inaveriguable lo que pregunta este articulo no obstante haberse practicado las más eficaces diligencias"3. Mayor diligencia demostrarían pocos años después, puesto que en el Vecindario de Ensenada de 1759 se nos mencionan, en un total de 9565 vecinos legos y 277 eclesiásticos seculares, un total de 124 pobres de solemnidad y 998 viudas pobres, lo que significa que el próspero Cádiz de mediados de la centuria contaba con unas bolsas de pobreza que afectaban, al menos, a la décima parte de la población ${ }^{4}$.

Ahora bien, es una discusión escolástica intentar un computo global del número de pobres existentes en el Cádiz dieciochesco, habida cuenta de que, en muchos casos esta población, más o menos marginal, escapaba del control de las autoridades. Más interesante nos parece, por el contrario, resaltar los rasgos estructurales de la miseria, que podríamos establecer en tres puntos principales: su volumen fluctuante, su polarización geográfica, y su focalización en unos colectivos muy concretos.

Ante todo, la pobreza no presenta unas fronteras numéricas claramente delimitadas, encontrándose su mayor o menor extensión en clara relación con las oscilaciones sufridas por el tráfico mercantil. Podríamos agregar mil testimonios al respecto, pero baste con indicar que, cuando en 1798 el obispo Antonio Martínez de la Plaza pretendía crear una junta para proporcionar trabajo a los numerosos desempleados existentes en la ciudad, lo hacia en atención de "aquellas clases a quienes la suspensión total del comercio y navegación tiene reducidas a la mayor estrechez"s. No perdamos de vista que el Cádiz dieciochesco, y ello es algo que ya ha sido señalado hasta la saciedad, era una ciudad con una estructura económica sumamente dependiente de la actividad mercantil, con una actividad industrial prácticamente inexistente si exceptuamos los sectores artesanales destinados a satisfacer las necesidades inmediatas de la población, y con amplios sectores de la misma trabajando en oficios de escasa o nula especialización ${ }^{6}$.

\footnotetext{
${ }^{3}$ GARCIA-BAQUERO GONZALEZ, Antonio, Cádiz 1753. Segín las Respuesias Generales del Catastro de Ensenada, Madrid, Tabapress, 1990, p. 147.

${ }^{4}$ Ibídem, p.79.

"Archivo Diocesano de Cádiz, Secretaria, legajo 50.

"GARCIA-BAQUERO GONZALEZ, Antonio, op,cit., PEREZ SERRANO, Julio, La población de Cádiz a fines dei Antiguo Régimen. Su estructura y mecanismos de renovación (1775-1800), Cádiz, Fundación Municipal de Cultura, 1989; Ibídem, Cádiz, la ciudad desnuda. Cambio económico y modelo demográfico en la formación de la Andalucia Contemporánea, Cádiz, Universidad, 1992.
} 
Pero no todos los ámbitos urbanos participaban por igual de la pobreza, lo que nos remitiría al segundo rasgo de la misma, a saber, su focalización geográfica. Es muy significativo, en este sentido, un informe enviado en 1805 por el obispo Francisco Javier de Utrera, según el cual existían en la ciudad un total de 6496 pobres (nuevamente la proporción de un $10 \%$ de la población gaditana), de los cuales 1418 se concentraban en la parroquia del Sagrario, 345 en la de San Antonio, 510 en la del Rosario, 329 en la de Santiago, y nada menos que 3894 en la de San Lorenzo?. Ello viene a significar que esta última parroquia reunía prácticamente el $60 \%$ de los pobres de la urbe, cuando, entre 1796 y 1800 los bautizados en la misma solamente suponían el $43,4 \%$ del total ${ }^{8}$. Lo que no es de extrañar, si tenemos en cuenta que estamos hablando de un sector de la ciudad caracterizado por sus altas densidades demográficas, hasta niveles de puro hacinamiento, y donde se concentra el grueso de la población artesana y menesterosa. $Y$ si seguimos con estos cálculos, nos daremos cuenta que la parroquia de Santa Cruz, o del Sagrario, concentra el $21 \%$ de los pobres, la del Rosario el 7,8\%, la de San Antonio el 5,3\%, y la de Santiago el 5\%, cuando el porcentaje de bautizados en las mismas ascendia, respectivamente, al $23,5 \%$, el $9,1 \%$, el $15,5 \%$, y el $4,2 \%$, siendo muy significativo que la feligresía de San Antonio, compuesta por numerosos comerciantes y extranjeros enriquecidos, y con unas débiles (relativamente) densidades de población urbana, presente los índices de pobreza, en relación a la población total, más reducidos de la ciudad.

Y, finalmente, la pobreza en el Cádiz dieciochesco es una realidad que golpea, preferentemente, a colectivos sociales muy concretos. Las mujeres, en este sentido, se nos aparecen como un grupo especialmente desfavorecido, habida cuenta de la débil tasa de ocupación femenina (en 1801 solamente trabajaba el $24,5 \%$ de la población activa) ${ }^{10}$, y el carácter poco especializado de los oficios por ellas ejercidos (costureras, criadas, sirvientas, etc). Ello provocaba una situación sumamente vulnerable en la que cualquier acontecimiento inesperado podía desembocar en una autentica tragedia vital. Ante todo, la muerte del cabeza de familia: en 1786 el $18 \%$ de las mujeres gaditanas eran viudas ${ }^{11}$, y es fácil deducir que una amplia proporción de las mismas se encontraba en una situación de total indefensión desde el punto de vista económico. En otras ocasiones el abandono del marido, atraido por el señuelo de una riqueza presumiblemente fácil en las Indias, lo que constituyo un fenómeno bastante frecuente en el Cádiz diecioches-

\footnotetext{
${ }^{7}$ Archivo Diocesano de Cádiz, Secretaria, legajo 58.

${ }^{8}$ PEREZ SERRANO, Julio, La población, p. 256.

"Ibidem, p. 86.

1" PEREZ SERRANO, Julio, Cádiz la ciudad desnuda, p.153.

"Ibídem, p. 135.
} 
$\mathrm{co}^{12}$. Sin olvidar la disolución del vinculo matrimonial ante la separación de sus componentes, que dejaría a las mujeres a merced de una pensión no siempre sufragada por el cónyuge ${ }^{13}$.

Un segundo colectivo especialmente proclive a la pauperización vendría constituido por el de la mano de obra poco especializada, que actuaría como un ejercito de reserva laboral en los años de prosperidad, y caería masivamente en el paro en épocas de mala coyuntura comercial. Se trataba de un colectivo bastante numeroso: pensemos que en 1753 la población activa gaditana ascendía a un total de 13826 personas, y en su seno encontramos, por ejemplo, a 704 mandaderos de espuerta, 1861 marineros, o 1169 sirvientes de seglares ${ }^{14}$. Y a la escasa especialización de esta mano de obra de reserva se añadía una remuneración bastante reducida: si aceptamos que el numero de días de trabajo al año computado por el Catastro de Ensenada era de unos 180 para los artesanos y 250 para los criados, y que unos salarios inferiores a los 1000 reales anuales suponían a mediados del siglo XVIII el límite de la pobreza y la marginación ${ }^{15}$, convendremos en el hecho de que un jornal igual o inferior a los cinco reales diarios, suponía un umbral bastante critico. Pues bien, amplios sectores de la masa laboral gaditana no llegaban a tan mágica cifra, a tenor de la pregunta treinta y tres del Catastro, encontrándose entre los mismos 555 peones, 203 barberos, 179 peluqueros, 704 mandaderos de espuerta y cordel, 884 sirvientes de seglares (aunque a éstos se les proporcionaba además la manutención ${ }^{16}$... y ello en una ciudad que siempre destacó por la carestía de cualquier artículo de consumo: podríamos citar multitud de testimonios al respecto, pero baste recordar un memorial dirigido en 1668 por el cabildo catedralicio a la regente Mariana de Austria en el que atribuía el disparatado coste de la vida al hecho de que todo en la ciudad, incluido el agua, había de ser traído del exterior ${ }^{17}$. El carácter inmigrante de buena parte de esta mano de obra ${ }^{18}$, con lo que ello conllevaba de no contar con unos marcos de solidaridad familiar que

\footnotetext{
${ }^{12}$ Cfr. PASCUA SÁNCHEZ, Maria José de la, Mujeres solas: historias de amor y de abandono en el mundo hispánico, Málaga, Universidad-Diputación, 1998, especialmente pp. 226ss.

${ }^{13}$ Cfr. MORGADO GARCIA, Arturo, "El divorcio en el Cádiz del siglo XVIII", Trocadero, 6-7, 19941995.

${ }^{14}$ Los datos de la estructura profesional gaditana han sido extraídos de GARCIA-BAQUERO GONZALEZ, Antonio, op. cit., pp. 56-65.

"AJ menos así lo asumen GONZALEZ BELTRẢN, Jesús, y PEREIRA IGLESIAS, José Luís, "Jerez de la Frontera en la Edad Moderna", CARO, Diego (coordinador), Fistoria de Jerez de la Frontera. Tomo Il. El Jerez Moderno y Contemporíneo, Cadiz, Diputación, 1999, p.156.

${ }^{16}$ GARCIA-BAQUERO GONZALEZ, Antonio, op.cit., pp. 128-142.

" DOMINGUEZ ORTIZ, Antonio, "Datos para la historia de Cádiz en el siglo XVII", Archivo Hispalense, 96, 1959.

18 Un ejemplo al respecto en PASCUA SANCHEZ, Maria José de la, "Los gallegos en el Cádiz de la Carreta de Indias. Balance secular de un proceso migratorio (1682-1778)", Migraciones internas y medium distance en la Peninsula Ibérica 1500-1900, volumen 2, Santiago de Compostela, Universidad, 1995.
} 
pudieran amortiguar la desgracia económica, tampoco contribuia, evidentemente, a mejorar la situación.

Por ultimo, un grupo de un reducido volumen numérico, pero de gran importancia cualitativa: los libertos. Durante buena parte del siglo XVIII persistió en la ciudad un significativo numero de esclavos, muchos de los cuales fueron liberados por sus amos no tanto por altruismo cuanto por haber llegado a una edad avanzada, y no aportar, por consiguiente, un gran provecho desde el punto de vista laboral, $y$, una vez obtenida la libertad, no había demasiadas alternativas a un horizonte de miseria. No es que podamos proporcionar demasiadas pruebas al respecto, pero es bien significativo que, según los libros parroquiales conservados en la Iglesia de Santa Cruz, entre 1701 y 1749 fallecieran en la ciudad 433 libertos, y solamente 17 realizaran testamento, to que supone un $4 \%$ sobre el total, cuando la media para el conjunto de la urbe oscila del $27 \%$ en 1700 , al $34 \%$ en 1725 y el $39 \%$ en $1750^{19}$, lo que nos indica que nos encontramos ante un grupo social especialmente desfavorecido, observación que podemos hacer extensible a todas las minorías raciales existentes en la ciudad: africanos, turcos, berberiscos...

\section{LA ESTRUCTURA BENÉFICA: LA SITUACIÓN PREEXISTENTE}

Ante tan poco halagüeño panorama, $y$, fuere por mero sentido de la caridad cristiana, por evitar tensiones sociales, o por incrementar clientelas e influencias (no olvidemos que "el patronazgo, la protección y la mediación proporcionaban canales obligatorios de acceso a la caridad, reforzando la posición social e incluso politica de los benefactores, mientras que incrementaban la incertidumbre e inseguridad inherentes a la vida laboral de los pabres...el propio proceso de una selección individual para la admisión y el abandono de las instituciones -cuya función ideal era inculcar los valores tradicionales del respeto y la sumisión-necesitaba una continua interacción entre la caridad y todos los niveles de la sociedad local" $)^{20}$, los grupos privilegiados de la sociedad gaditana hubieron de dar una respuesta. Respuesta, naturalmente, condicionada por unas claves ideológicas muy concretas, caracterizadas por el predominio del componente espiritual sobre el material, lo que se refleja en la importancia concedida a las atenciones espirituales, y el carácter conventual de la vida cotidiana de los asistidos. La admisión en los centros benéfícos esta muy controlada, primando los vínculos de influencia social propiciados por las relaciones de patronazgo y las recomenda-

\footnotetext{
19 PASCUA SÁNCHEZ, Maria José de lá, Vivir la muerte en el Cádiz del Setecientos (1675-1801) Cádiz, Fundación Municipal de Cultura, 1990, p. 28.

wo WOLF, Stuart, op. cit., p. 44.
} 
ciones directas, a lo que se añade la preferencia manifestada por los residentes (en opinión de Stuart Woolf, "en las sociedades organizadas sobre explicitos valores de honor, status y familia, y que funcionaban por medio de mecanismos de patronazgo, protección y recomendación, la residencia era una condición necesaria para una confianza cimentada en el conocimiento personal o indirecto del carácter, el comportamiento y las necesidades del individuo") ${ }^{21}$ y vecinos en la urbe, favoreciéndose a los asalariados y a los pobres oficialmente reconocidos como tales, e ignorándose a vagabundos y malentretenidos ${ }^{22}$.

La situación de la beneficencia era de una gran complejidad, pero, en líneas generales, podemos establecer tres niveles diferentes. En primer lugar, lo que podriamos llamar la caridad espasmódica, constituida por las limosnas proporcionadas coyunturalmente, bien a título individual, bien institucionalmente. En este ultimo sentido podríamos citar al municipio gaditano, si bien éste nunca se destacó por su desmedida generosidad: durante el reinado de Carlos III sus gastos benéficos apenas se limitaban a la suma de 3300 reales anuales para los expósitos y una cantidad similar para el Hospital de Mujeres, en claro contraste con las elevadas sumas invertidas en ceremonias y festividades litúrgicas ${ }^{23}$. Un papel más importante debió jugar la Iglesia, especialmente los obispos, que en la mayor parte de los casos respondieron perfectamente al modelo de prelado ideal contrarreformista, caracterizado por su talante limosnero: podríamos multiplicar los testimonios en este sentido, pero baste recordar en este sentido la generosidad de Fray Tomas del Valle (1730-1776), que en los últimos años de su vida llegó a repartir en un sólo día más de 10.000 pesos de limosnas, procediendo buena parte de estas sumas de donativos proporcionados por los adinerados comerciantes de la urbe ${ }^{24}$. O la de José Escalzo y Miguel (1783-1790), que repartía mensualmente 50 pesos al Hospicio, donaba 500 reales anuales al Hospital de San Iuan de Dios, y daba todas las semanas 205 reales a los curas de la ciudad para que los repartiesen entre los pobres vergonzantes ${ }^{25}$. Y no podemos olvidar tampoco a muchos vecinos de la ciudad que en sus disposiciones testamentarias realizaron distintos legados caritativos: la media para todo el siglo XVIII es de un 19\% de los testadores, aunque sus preferencias se destinaron mas a los edificios e insti-

\footnotetext{
"Ibídem, P. 35.

"LOPEZ MORA, Fernando, "Claves ideológicas del modelo asistencial practicado en los hospitales cordobcses de Jesús Nazareno a fines del siglo XVI", Actas del Congreso Internacional Cristóbal de Sanla Calalina y las cofradias de Jesís Nazareno, volumen 1, Córdoba, 1991.

"3USTOS RODRÍGUEZ, Manuel, "La hacienda municipal gaditana en el reinado de CarIos III", Gades, 9, 1982, pp. 43-44.

${ }^{24}$ ANTÓN SOLE, Pablo, La lglesia gaditana en el siglo XVIII, Cádiz, Universidad, 1994, p. 168.

${ }^{2}$ Archivo Diocesano de Cádiz, Varios, legajo 2303, "Copia de las cartas del expolio y vacante del Ilustrisimo Señor D. Josef Escalzo y Miguel”, fol. 5.
} 
tuciones eclesiásticas que a los propios pobres ${ }^{26}$. Es difícil cuantificar el monto total de todas estas aportaciones dispersas, pero la inoperancia a la larga de este tipo contribuciones hay que basarlo, más que en un reducido volumen económi$\mathrm{co}$, en su carácter arbitrario y coyuntural.

No podemos olvidar, dentro de las instituciones que practican esta caridad circunstancial, la labor realizada por las cofradías. Su impacto parece haber sido reducido, por cuanto la labor asistencial de las hermandades en muy pocas ocasiones trasciende el carácter de seguro de entierro de sus hermanos, pero no está de más recordar que la Cofradía del Santo Cristo de la Misericordia destinaba una parte de las limosnas recogidas "para levantar a las pecadoras arrepentidas que del infeliz estado de la culpa querian reducirse a las claras luces de la gracia", en tanto que la de Nuestra Señora de los Desamparados asistía con alimentos a los reclusos pobres ${ }^{27}$. Pero nada de ello es comparable a la labor realizada por la Hermandad de la Santa Caridad ${ }^{28}$, que en sus constituciones de 1717 fijaba como actividades benéficas el recoger a los enfermos pobres y conducirlos a los hospitales de la ciudad, la recogida de los pobres desvalidos que cayeran enfermos por las calles, proporcionar digna sepultura a los ajusticiados, y enterrar los huesos que se encontrasen dispersos por playas y campos ${ }^{29}$, siendo además de su responsabilidad, en cuanto administradora del Hospicio de Santa Elena, el socorrer a los sacerdotes pobres y a los peregrinos. Dotada de un fuerte carácter aristocrático (la cuota de ingreso ascendía a cien reales), se benefició en más de una ocasión de la generosidad de un cabildo municipal ${ }^{30}$ del que muchos de sus componentes eran a su vez miembros de la Hermandad (en 1714 pretendieron acceder a ella apellidos tales como Soto, Ravaschiero, Colarte, Sopranis, Lila, y los marqueses de Montecorto y del Pedroso) ${ }^{31}$, su acción benéfica se centraría progresivamente en la administración del Hospicio de Santa Elena.

Un segundo arbitrio estaría constituido por una serie de fundaciones piadosas que no se materializan físicamente en edificio alguno. Hablamos de los

\footnotetext{
: PASCUA SÁNCHEZ, Maria José de la, Vivir la muerte, pp. 229ss.

"MORGADO GARCIA, Arturo, "Cofradias y hermandades en el Cádiz de los siglos XVII y XVIII", Actas de los VIl Encuentros de Historia y Arqueología. Gremios, Hermandades y Cofradias, San Fernando, Fundación Municipal de Cultura, 1992, p. 55.

:x Sus constituciones, en Reglas de la muy humilde Hermandad de la Santa Caridad de Nuestro Señor Jesucristo y Patrocinio del Glorioso Arcángel San Miguel, Cádiz, 1905. Ejemplar en la Biblioteca de Temas Gaditanos.

29 Descripciones de esta ceremonia en ANTÓN SOLE, Pablo, "La procesión de los hucsos", Archivo Hispalense, 1958, pp. 129-130, y PASCUA SÁNCHEZ, María Josế de la, Actitudes ante ia muerte en el Cádiz de la primera mitad del siglo XVIII, Cádiz, Diputación, 1984, pp. 175-176.

" MORGADO GARCIA, Arturo, Iglesia y sociedad en el Cádiz del siglo XVIII, Cádiz, Universidad, 1989 , pp. 220-221.

"Archivo Diacesano de Cádiz, Varios, legajo 1865, "Autos...sobre la reformación de la Hermandad y cofradia de la Santa Caridad".
} 
Patronatos de Obras Pías, cuyo status adolece de cierta ambigüedad: se trata de instituciones fundadas por particulares, normalmente a través de una disposición testamentaria, en la que se establecen los fines de la fundación y las rentas que aseguraran su mantenimiento, corriendo su administración posterior a cargo, normalmente, de alguna institución eclesiástica o del municipio.

Su número no era, en absoluto, despreciable: hacia 1799 , poco antes de los procesos desamortizadores, existían en Cádiz un total de 71 Patronatos de Obras Pías, con unas rentas globales que alcanzaban la suma de 1.632 .915 reales (cifra superior, como veremos, a la de cualquier institución benéfica de la ciudad ${ }^{32}$. Las diferencias económicas existentes eran, no obstante, bastante significativas: solamente cuatro de ellos superaban unos 100.000 reales anuales, tratándose de los fundados por Pedro de la $\mathrm{O}^{33}$, Juan Fragela ${ }^{34}$, el deán Lorenzo Ibáñez Porcio ${ }^{35}$, y Nicolás Fernández del Castillo. Estas fundaciones, databan, en bastantes ocasiones, de muchos años atrás, $y$, de hecho, según un Libro de fundaciones y patronatos que data del siglo XVIII conservado en el Archivo Diocesano, y que recoge un total de 67 fundaciones, 34 habían sido fundados antes de 1700 y solamente 8 después de dicha fecha, no constando el momento de creación de los restantes ${ }^{36}$.

De mayor interés nos parece señalar que, por medio de la administración de los Patronatos de Obras Pías, las élites sociales de la ciudad se involucraban de forma muy estrecha en la administración de la beneficencia, con lo que ello conlleva de captación de agradecimientos y deudos: la principal beneficiaria era, $\sin$ duda alguna, la Iglesia, bien sean los obispos, el cabildo catedralicio o los conventos, pero también existen patronatos en los cuales la responsabilidad de la administración recaía sobre el ayuntamiento (podemos destacar al respecto el fundado por Melchor de Cuellar) ${ }^{37}$ o alguna cofradía. Las orientaciones de su acción caritativa también estaban claramente dirigidas: destaca ante todo el casamiento de doncellas pobres y huérfanas y el rescate de cautivos, acciones situadas muy por delante de la concesión de limosnas a los pobres vergonzantes. Todo ello nos muestra una intención muy clara de lograr la inserción de las mujeres en la sociedad por medio del acceso al estado matrimonial, lo que parece ser el fin

\footnotetext{
"Archivo Catedralicio de Cádiz, Sección 10, Libro de Subsidio de 1777-1802.

"Mencionado por CRUZ Y BAHAMONDE, Nicolás, Conde de Maule, De Cádiz y su comercio. Tomo XIII del Viaje de España, Francia e ltalia, edición de Manuel Ravina Martín, Cádiz. Universidad, 1997, p. 163.

3 "Sobre esta fundación, PASCUA SÁNCHEZ, Maria José de la, "La fundación de la "Casa de Viudas" de Cádiz. El gesto caritativo de Juan Clat (Fragela), un comerciante de Damasco", La burguesia de negocios en la Andalucía de la Ilustración, tomo II, Cádiz, Diputación, 1991.

${ }^{35}$ Noticias sobre el mismo en MORGADO GARClA, Arturo, "El alto clero gaditano durante el Antiguo Régimen", Studia Histarica, 16, 1997, p.251.

"Archivo Diocesano de Cádiz, Manuscritos, libro 437.

${ }^{37}$ La escritura fundacional en Archivo Municipal de Cádiz, Actas Capitulares, Libro 18, fols. 20v-36.
} 
primordial de todas estas instituciones. Hay, asimismo, un claro sentimiento de linaje, por cuanto es frecuente que, para beneficiarse de la labor bienhechora del patronato en cuestión, hubiera que demostrar la vinculación familiar con el fundador.

No existe ningún estudio global sobre la acción caritativa de los patronatos gaditanos, $y$, en el estado actual de nuestros conocimientos, tan sólo podemos aportar noticias dispersas. Sabemos que el fundado por Antonio Mendíbur proporcionó entre 1714 y 1749 dotes por un valor de 19.841 reales a 3864 doncellas pobres y casaderas ${ }^{38}$. O que entre 1738 y 1786 el de Juan de los Reyes y Silva concededría dotes a 97 huérfanas y 22 religiosas $^{39}$. O que el de Pedro de la $O$ invirtió entre 1717 y 1768 un total de 737.237 reales en los 36 años de este periodo de los que tenemos noticias ${ }^{40}$. De estos datos, no obstante, podemos deducir que los patronatos realizan una acción caritativa extensiva: de lo que se trata, ante todo, es de crear una amplia red de beneficiarios, con la clara finalidad, explícita o inconsciente, de aumentar la proyección social de la institución encargada de su administración.

Finalmente, la acción caritativa en el Cádiz dicciochesco se ejercía a través de lo que podemos denominar beneficencia institucionalizada, plasmada en edificios con una función especifica, unas rentas concretas, y un personal a su servicio más o menos numeroso. Las incidencias que movieron a su fundación ya las hemos recogido en otro lugar ${ }^{41}$, y su gama es bastante bien conocida: la Casa de los Niños Expositos ${ }^{42}$, las Casas de Viudas fundadas por Diego de Barrios ${ }^{43}$ y Juan Fragela (esta última sería una aportación de nuestra centuria) ${ }^{44}$, la Casa de Recogidas de San Pablo ${ }^{45}$, el Hospital de San Juan de Dios para varones y el

\footnotetext{
18 Archivo Diocesano de Cádiz, Manuscritos, libro 75.

"Archivo Diocesano de Cádiz, Varios, legajo 352.

* Archivo Diocesano de Cádiz, Manuscritos, libro 40.

"MORGADO GARCIA, Arturo, El estamento eclesiástico y la vida espiritual en la diócesis de Cádiz en el siglo XVII, Cádiz, Universidad, 1996, pp. 227ss. Resulta de suma utilidad al respecto CONCEP. CIÓN, Fray Jerónimo de la, Emporio de el Orbe. Cádiz llustrada, Ámsterdam, 1690.

12 Una panorámica sobre la misma en PEREZ SERRANO, Julio, "La Casa de Expósitos de Cádiz en la primera mitad del siglo XIX: avances y retrocesos de la reforma liberal en el sistema benéfico", Trocadero, 3, 1991.

${ }^{43}$ Escritura de fundación en Archivo Histórico Provincial de Cádiz, Beneficencia, legajo 1612, escritura 98.

*4 Vid. PASCUA SÁNCHEZ, Maria José de la, "La fundación”...Sus constituciones impresas en Fundación y constituciones de la Casa Pía de pobres viudas y doncellas huérfanas advocación de San Juan Bautista y San Pedro Apóstol, reimpresión, Cádiz, 1805. Ejemplar en la Biblioteca de Temas Gaditanos.

4. Escritura de fundación en Archivo Histórico Provincial de Cádiz, Beneficencia, legajo 1613, escritura 42. El obispo Fray Tomas del Valle fundaría en 1738 un patronato para que en el seno de esta casa se educasen seis muchachas naturales y vecinas de la ciudad (ANTÓN SOLE, Pablo, La Iglesia, p. 463).
} 
Hospital de Nuestra Señora del Carmen para mujeres ${ }^{4 b}$, y, finalmente, el Hospicio de Venerables Sacerdotes de Santa Elena, a cargo de la Hermandad de la Santa Caridad desde $1715^{47}$.

Es de señalar que buena parte de estas instituciones están destinadas especificamente al colectivo femenino. En primer lugar, por ser uno de los más sensibles ante cualquier proceso de pauperización. Pero también por motivos de orden ideológico: se busca lograr la reinserción y la reeducación de un grupo especialmente proclive al pecado, y no es casual, en este sentido, que la disciplina interna de buena parte de estos centros se caracterice por un perfil claramente monacal. En la Casa de Viudas de Fragela (donde el fundador había prohibido la entrada a revoltosas, inquietas, enredadoras, chismosas, mujeres mundanas y viandantes), las visitas masculinas eran despedidas a las doce en el mediodia y al toque de oración por la tarde, disponiéndose además que las moradoras han de vivir cada una en el cuarto, o habitación de su destino, en toda quietud, sosiego y santo temor de Dios, aplicadas a el ejercicio o ministerio que tengan, sin causar ruidos, alborotos, riñas ni escándalos... en santa paz y con fraternal amor $y$ caridad entre todas, asistiéndose unas a otras en las enfermedades y urgencias, debiendo concurrir al Oratorio de la casa en las horas de oración $n^{48}$. En la Casa de Viudas fundada por Manuel Barrios Leal, las constituciones de 1676 prohibían conversaciones de dia ni de noche con hombres aunque sean parientes que redunde en desorden, nota, escándalo o murmuración, y se disponía el rezo del rosario todas las noches ${ }^{49}$. La Visita Pastoral de 1774 realizada a la Casa de San Pablo insistía en que el general objetivo de su creación es el recoger a las mujeres que se han pervertido en el mundo ofendiendo al Señor con delitos de deshonestidad e impureza $a^{30}$.

Su eficacia se veía disminuida, en líneas generales, por una financiación claramente insuficiente, consecuencia de la débil base patrimonial de estas instituciones. No nos dejemos engañar por los ingresos reflejados en el Catastro de Ensenada, que nos muestra cómo las rentas del Hospital de San Juan de Dios

\footnotetext{
"Vid, GOENECHEA Y ALCALA ZAMORA, Luis, Una hospitalización singular en la medicina ilustrada española: el Hospital de Mujeres de Cádiz 1733-1919, Cádiz, 1986, Facul tad de Medicina, Tesis doctoral inédita. Su habitación definitiva data del siglo XVIII, puesto que la marquesa de Campo Alegre, Doña Jacinta Armengual de la Mota (hermana de Lorenzo Armengual, obispo de la ciudad entre 1715 y 1730) dejó en su testamento la suma de 12.000 pesos para que se construyese un edificio mas digno, que seria finalmente inaugurado en 1749. A Fray Tomas del Valle se le deben unas ordenanzas para su gobierno que serian publicadas en 1783 .

"Archivo Diocesano de Cádiz, Varios, legajo 1865, "Autos fechos de pedimento de don Pedro Xínénez Parrado presbítero administrador del Hospicio de Venerables Sacerdotes".

"PASCUA SÁNCHEZ, Maria José de la, "La fundación”, pp. 293-294, 297.

*" Archivo Histórico Provincial de Cádiz, Beneficencia, legajo 1612, Escritura 98.

5" Archivo Diocesano de Cádiz, Secretaria, legajo 505, "Expediente para la visita de las iglesias auxiliares, ermitas y casas de piedad".
} 
ascendían a 130.551 reales, las del Hospital de Mujeres a 64.827, y las del Hospicio de Santa Elena a $22.272^{51}$, por cuanto las dotaciones económicas de estos centros eran claramente insuficientes, y la situación deficitaria, algo común. Los ingresos de la Casa de Recogidas de San Pablo, por ejemplo, ascendían entre 1775 y 1779 a 239.189 reales y los gastos a 302.956 . Idéntica situación vivía la Casa de Niños Expositos: entre 1785 y 1789 sus ingresos ascendieron a 748.461 reales y los gastos a 1.034.305. Por lo que respecta al Hospital de Nuestra Señora del Carmen, en 1790 tenía unas deudas atrasadas de 99.871 reales. Una gestión, en algunos casos corrupta e ineficaz, tampoco ayudaba mucho a resolver los problemas: en 1786 la autoridad episcopal se vio obligada a exigir la dimisión de Juan Servois, administrador de la Casa de Recogidas de San Pablo, por su mala administración ${ }^{52}$. Las consecuencias de esta escasez de recursos podian resultar a veces trágicas: entre 1785 y 1789 ingresaron en la Casa de Expósitos un total de 2067 niños, de los que 1442 fallecieron ${ }^{53}$. El Hospital de Mujeres conoció en todo el siglo XVIII 10837 fallecimientos sobre un total de 52254, lo que supone una tasa de mortalidad ligeramente superior al $20 \%$ s4. No menos trágica resultaba la excesiva dependencia económica de limosnas y donaciones proporcionadas por los bienhechores: según el Catastro, nuevamente, el Hospital de San Juan de Dios conseguía sobrevivir gracias a la caridad cristiana con las limosnas que franquea, y el Hospicio de Santa Elena se veía obligado a que los hermanos de la Santa Caridad suplieran con sus donaciones los frecuentes déficits ${ }^{55}$.

Toda esta organización servía asimismo para incrementar la proyección social de la Iglesia, que, ciertamente, no había sido, las más de las ocasiones, la fundadora de estas instituciones, pero sí la responsable de su mantenimiento. Si exceptuamos los casos de la Casa de Viudas de Barrios, donde el patronato recaía en el mayorazgo creado por el fundador ${ }^{56}$, y el Hospicio de Santa Elena, a cargo de la Hermandad de la Santa Caridad, las restantes instituciones benéficas de la ciudad estaban controladas por la Iglesia, sea la Orden de San Juan de Dios (el hospital homónimo), el cabildo catedralicio (la Casa de Viudas de Fragela) o la autoridad episcopal (el Hospital de Nuestra Señora del Carmen, la Casa de Recogidas de San Pablo, y la Casa de Niños Expósitos). No es por ello extraño que una de las principales preocupaciones de la jerarquía episcopal fuese todo lo

\footnotetext{
"GARCIA-BAQUERO GONZALEZ, Antonio, op. cit., p. 114.

"MORGADO GARCLA, Arturo, Iglesia y Sociedad, pp. 219-220.

"Archivo Diocesano de Cádiz, Secretaria, Edictos impresos, número 97.

"GOENECHEA Y ALCALA ZAMORA, Luis, op. cit., pp. 197-199. En comparación, la mortalidad en el Hospital Real de Santiago ascendió al 9,6\% en 1735-1750 y al 12,8\% en 1793-1800 (GARCIA GUERRA, Domingo, El Hospital Real de Santiago (1499-1804), La Coruna, 1983, pp. 74 y I05).

"GARCIA-BAQUERO GONZALEZ, Antonio, op. cit, p. 114.

${ }^{s 6}$ Archivo Histórico Provincial de Cádiz, Beneficencia, legajo 1612, escritura 98. Maule señala que correspondia al patronato de Tabares (op. cit., p.197).
} 
relativo a la situación espiritual de estos centros: en la visita realizada en 1774 al Hospicio de Santa Elena, se ordenaba que los capellanes llevasen un padrón de los residentes a fin de comprobar el cumplimiento pascual, a la vez que se les exhortaba a "cuidar y velar sobre todas las materias espirituales como son confesiones, comuniones, explicación de la doctrina cristiana, platicas, sermones, el santo sacrificio de la misa, evitando escándalos y pecados"s?.

\section{LA IMPLANTACIÓN DEL MODELO DE BENEFICENCIA ILUS- TRADO: EL HOSPICIO ${ }^{\text {s8 }}$}

La implantación en Cádiz del modelo ilustrado de beneficencia, caracterizado, a grandes rasgos, por su visión carcelaria, represiva y productivista de la pobreza ${ }^{39}$, tendría su ejemplo mas acabado en el paso del Hospicio de Santa Elena de la administración de la Santa Caridad a la jurisdicción del Consejo de Castilla merced al Real Despacho del 11 de febrero de 1775, que apartaba del gobierno al hermano mayor de dicha hermandad para ponerlo a cargo de una junta de doce miembros presidida por D. Juan de Mérida, presidente interino de la Contratación ${ }^{60}$. La Real Presentación del 20 de mayo de 1785 aprobaría unas nuevas ordenanzas absolutamente imbuidas del espiritu ilustrado ${ }^{61}$, por cuanto, al referirse a las finalidades de la institución, mostraba entre las mismas "el socorro de los verdaderos necesitados, su instrucción cristiana y civil, su aplicación al trabajo, el apartar de la vista de los hijos de familia la ociosidad, los vicios y el mal ejemplo, el promover y proporcionar auxilios a los vecinos pobres del pueblo para que puedan, con su aplicación al trabajo, ganar el sustento, adelantar y perfeccionar la industria popular y quitar de raiz los pretextos que fingen los

\footnotetext{
${ }^{57}$ Archivo Diocesano de Cádiz, Secretaria, legajo 505, "Expediente..."

"s MORGADO GARCIA, Arturo, "La reforma de la Beneficencia en el Cádiz del siglo XVIII: el Hospicio (1785-1808)", Trocadero, 3, 1991.

${ }^{50}$ La bibliografía sobre estas cuestiones es muy amplia, pudiendo destacar CARASA SOTO, Pedro, "La asistencia social en el siglo XVIII español. Estado de la cuestión", Coloquio Internacional sobre Carlos III y su siglo, Madrid, Universidad Autónoma, 1990; MAZA ZORRILLA, Elena, Pobreza y asistencia social en España siglos $X V I$ al $X X$, Valladolid, Universidad, 1987; PEREZ ESTÉVEZ, Rosa Maria, El problema de los vagos en la España del siglo XVIII, Madrid, Confederación Española de Cajas de Ahorros, 1276; REYES LEOZ, José Luis de los, "Carlos III padre de vasallos", EQUIPO MADRID, Carlos III, Madrid y la Ilustración, Contradicciones de un proyecto reformista, Madrid, Siglo XXI, 1988; VELAZZUEZ MARTINEZ, Matías, Desigtaidad, indigencia y marginación social en la España Ilustrada. Las cinco clases de pobres de Pedro Rodríguez Campomanes, Murcia, Universidad, 1991

${ }^{60}$ ANTÓN SOLE, Pablo, Situración económica y asistencia social de la diócesis de Cádiz en la segunda mitad del siglo XVIII, Cádiz, Caja de Ahorros, 1985, p. 158.

ś Ordenanzas para el gobierno de la Casa de Misericordia de la ciudad de Cádiz aprobadas por S.M. y Señores de su Real y Supremo Consejo de Castilla, Cádiz, 1785. Ejemplar en la Biblioteca de Temas Gaditanos.
} 
vagos y malentretenidos para conseguir sus malos fines y engañar a los jueces y piadosos, usurpando las limosnas que solo corresponden a los verdaderos pobres". Es decir, so pretexto de ayudar a los verdaderos pobres, se penaliza la limosna y el vagabundeo, insistiéndose en hacer de los internos buenos cristianos, buenos súbditos, y buenos trabajadores.

La vida interna, más que al modelo monacal, responde a un modelo semicarcelario, restringiéndose la libertad de movimientos hacia el exterior, e implantando una rigurosa disciplina en el interior, previéndose incluso la existencia de un Departamento de Corrección de Costumbres al cual serian destinadas las mujeres que diesen escándalo publico, los hombres destacados por su pereza o sus hábitos viciosos, los hijos desobedientes o irrespeturosos para con sus padres, y los mendigos que pidieran limosna contradiciendo las Reales Ordenes. Se establecía separación de sexos y edades, la comida y el vestuario se limitaba a proporcionar la subsistencia y el abrigo más imprescindibles, se pasaba revista semanal del trabajo realizado y se permitía la salida de la institución tan sólo a aquéllos que demostrasen su reinserción social: los pobres adultos debían recobrar la salud o conseguir personas que los mantuviesen, los niños serian enviados a trabajar con artesanos, y se procuraría casar a las niñas con menestrales aplicados y de buenas costumbres, proporcionando el Hospicio la suma necesaria para la dote.

El gobierno de la institución daba cabida en su seno a las élites sociales de la urbe gaditana: de hecho, la Junta de Gobierno estaba presidida por el Gobernador, y sus doce vocales eran dos regidores perpetuos del cabildo, un representante del cabildo catedralicio, uno de los curas de la Santa Iglesia Catedral, y ocho vecinos "de conocido celo, talento y caudal", es decir, la burguesía mercantil gaditana. La Iglesia seguía haciéndose responsable de la vida espiritual de la institución, a la que se le concedía una gran importancia, y, de hecho, las visitas pastorales siguieron produciéndose aun después del pase del Hospicio a la jurisdicción del Consejo de Castilla.

El número de internos en el Hospicio siempre fue bastante elevado: en 1787 había un total de 830 , cifra que en 1800 se reducía a 693 , figurando entre los mismos 62 ancianos, 171 ancianas, 139 niños, 203 niñas, 33 "personas de matrimonios", 43 dementes y 34 sirvientes y empleados. Hacia todos ellos la Junta de Gobierno tenia muy claros los objetivos a perseguir, manifestando en 1786 una gran dosis de autocomplacencia, por cuanto se refería a como "se ve en el dia extinguida la mendiguez, socorridos los pobres de ambos sexos y matrimonios, recogidos los muchachos y muchachas, recibiendo una educación cristiana $y$ politica con la frecuente y profunda instrucción en la doctrina y máximas de reli- 
gión y en la asidua aplicación al trabajo en que se ocupan mediante el establecimiento de manufacturas oportunas, artes y oficios arraigados ya en la casa".

Uno de los grandes hándicaps de la institución radicaba en la debilidad de sus bases económicas y, si bien el Hospicio contaba con una cierta base patrimonial (una veintena de casas y asesorías, los réditos de algunos censos, y las rentas de algunos patronatos de Obras Pías), el grueso de sus rentas venia proporcionado por las limosnas y donaciones, y los arbitrios aplicados por la corona, entre ellos el derecho de un real por cada fanega de trigo que se consumiera en la ciudad, y una asignación procedente de la Real Lotería. Todo ello nos muestra que los ingresos de este centro se caracterizan por su fuerte dependencia de la coyuntura y por su inestabilidad, lo que nos explica su progresivo endeudamiento. En cualquier caso, el Hospicio era la institución benéfica de la ciudad con unas rentas más elevadas, superando sus ingresos anuales en los últimos años del siglo XVIII la cifra de un millón de reales.

Pero el aspecto más significativo del Hospicio radica en el intento de productivizar la estancia de los residentes por medio del establecimiento de manufacturas, aplicadas, naturalmente, a procesos productivos simples; así, Townsend nos cuenta que la institución disponía de cuarenta y cinco telares, dieciséis máquinas de hacer calcetines, tornos de hilar a mano, bancos de trabajo, herramientas de carpinteros, torneros, zapateros y sastres, un molino de rueda, una hiladora con varios husos, y una máquina para cardar algodón ${ }^{62}$. Pero todo ello constituyó un fracaso económico: la implantación de manufacturas requería una fuerte inversión previa en la compra de materia prima, maquinaria, y contratación de maestros artesanos, y ello no seria compensado con la venta al mercado de los géneros producidos (según Townsend, "esta acumulación de productos en los almacenes se debe a la falta de mercado. Como los organismos públicos dejan mucho que desear en lo que se refiere al control, al celo y al dinamismo que ejercen e imprimen sobre todas sus iniciativas, solo pueden encontrar salida a lo que producen cuando lo venden sensiblemente más barato que los fabricantes particulares...en todas las partes las personas confinadas y privadas de libertad comen mucho y trabajan muy poco. Este es, sin duda, el caso del Hospicio de Cádiz, donde se celebran noventa y dos dias de fiesta y se gasta en alimentación y en ropa el doble de lo necesario") $)^{63}$, los cuales, de hecho, normalmente se acumularon en los almacenes de la institución y tan sólo se utilizaron para el pago de deudas penđientes. Había además otras razones de fondo: la desgana y la escasa aplicación con la que siempre se respondía a cualquier sistema de trabajo obligatorio, y el bloqueo inglés, iniciado en 1797, que tanto dañaría a la economía de la

${ }^{2}$ TOWNSEND, Joseph, Viaje por España en 1786-1787, Madrid, Turner, 1989, p.288.

"Ibídem, pp.289-290. 
ciudad. En 1798 la Junta directiva disponía el cese de la actividad en los talleres, aunque esta decisión no debió ser bien entendida por todos los sectores ilustrados de la ciudad: de hecho el conde de Maule opinaba "aunque la Junta suspendió las fábricas, no puede dejar de conocer que son esencialmente necesarias algunas labores para el entretenimiento y ocupación de tantos brazos. Si el conde $O^{\prime}$ Reilly las montó en grande con demasiado lujo, un sistema económico-doméstico, sin fatigar demasiado a los individuos e interesándolos en una tercera parte, las ptiede arreglar al consumo de la misma casa y de las gentes pobres de la ciudad"64. Lo cierto es que los resultados de la implantación del modelo ilustrado de beneficencia en la ciudad fueron bastante mediocres, a tenor de las vicisitudes conocidas por el Hospicio. Aunque se consigue un edificio imponente y con un elevado número de recogidos, las principales finalidades fracasaron por completo, a saber, el intento de productivizar la pobreza y la eliminación de la mendicidad en la ciudad.

\section{LA ALTERNATIVA ECLESIÁSTICA: LA HOSPITALIDAD DOMESTICA}

Algunos sectores de la Iglesia gaditana asumieron con entusiasmo el nuevo modelo de beneficencia, siendo el ejemplo más claro al respecto el del canónigo penitenciario Cayetano Huarte, que formó parte de la Junta directiva del Hospicio $^{65}$. Nuestro hombre llegaría incluso a predicar un sermón solicitando apoyo para el mismo, donde podemos leer frases tales "Qué felices serian los pueblos todos, si en todos pudiese establecer la Iglesia ese espiritu de caridad, y disciplina. Si en todos pudiera hacerse cargo de recoger los pobres para que nadie necesitara, para que floreciera una caridad ilustrada en los ricos, para reparar de una vez los perjuicios que el Estado, y la Religión, necesariamente han de sufrir en una mendicidad sin sujeción, ni freno, en una ociosidad voluntaria, en la falta de educación...una piedad sólida, verdadera, útil...juzgará a los pobres con justo discernimiento, conocerá de sus necesidades, y preservará a los hijos de los mendigos....libertará a el verdaderamente necesitado, a el que no tenía quien le ayudase...las almas de los pobres entrarán en el cumplimiento de la Ley del Señor, que habian abandonado....sacará los pobres de los vicios, de la abominación e iniquidad en que vivian por lo común, y este nombre de mendigo, de pobre, que se miraba con ceño, con desprecio, será un nombre de veneración y respeto... reconoced lo ventajoso, lo útil de ese establecimiento, ejercitad en él

\footnotetext{
CRUZ Y BAHAMONDE, Nicolás de la, op.cit., p. 194.

"MORGADO GARCIA, ATturo, Iglesia e Ilustración en el Cádiz del siglo XVIII. Cayetano Huarle (1741-1806), Cádiz, Universidad, 1991, pp. 79-81.
} 
toda la caridad que podáis"66. Pero la actitud del canónigo no se encontraba ni mucho menos generalizada entre sus camaradas, y ello se plasmaría muy claramente en la reunión del cabildo catedralicio celebrada el 2 de abril de 1787 , en el que figuraba como punto del orden del dia lo que debía contestarse al Consejo de Castilla acerca de la aplicación de las obras pías destinadas a limosnas a favor del Hospicio, siendo Huarte el único partidario de ello ${ }^{67}$. No hay que entender todo esto como una muestra de tacañería del cuerpo capitular: de lo que se trataba en el fondo, con el pretexto de respetar la voluntad de los fundadores de las obras pías, era de quien iba a controlar estas sumas, con lo que ello suponía de generar una clientela de paniagudos y agradecidos.

Lo que sí estaba claro es que la fundación del Hospicio amenazaba seriamente el monopolio que hasta el momento había realizado la Iglesia de las actividades benéficas, $\mathrm{y}$ algunos sectores debieron pensar que era conveniente volver a tomar la iniciativa. La oportunidad vendría dada por la crisis económica producida en los años noventa, fecha en la que el obispo Antonio Martínez de la Plaza volvía a encauzar la beneficencia eclesiástica utilizando un arbitrio no muy querido por los ilustrados: la asistencia a domicilio. Ello se plasmaría en la creación de la Hospitalidad Domestica, cuyo nacimiento hay que situarlo en 1792, fecha en la que se le ocurría al prelado "establecer unas Juntas en las feligresías de las parroquias de esta ciudad con el titulo de Hospitalidad Domestica para socorro de enfermos pobres desvalidos" ${ }^{96}$. El sistema estaba centralizado en manos del obispo, existiendo unas juntas en cada parroquia presididas por los curas que, en atención a las necesidades, repartirian a domicilio las limosnas recogidas, cuyo importe fue bastante respetable: entre 1793 y 1810 se recogerían un total de 1.694.738 reales de limosnas con las que se pudo atender a 54.965 enfermos (nuevamente, observamos la preferencia por una caridad extensiva), aunque más del $60 \%$ de los mismos fueron socorridos en el fatídico año de 1800 , momento en el que la fiebre amarilla asoló la ciudad. Las iniciativas del prelado no finalizaron aquí, sino que en 1798 se organizaba una junta para socorrer a "aquellas clases a quienes la suspensión total del comercio y navegación tiene reducidas a la mayor estrechez", gastándose las limosnas obtenidas (que ascendieron a 466.883 reales entre el 22 de abril de 1798 y el 20 de marzo de 1800 ) preferentemente en el pago de jomales a los obreros que trabajaban en la construcción de la nueva cárcel, y en el reparto de pan a los necesitados ${ }^{59}$.

\footnotetext{
"HUARTE, Cayetano Maria de, Santa Disciplina de la Iglesia sobre el modo más perfecto de distribuir la limosna..., Cádiz, Juan Ximenez Carreño, 1784, pp. 40-43.

${ }^{67}$ MORGADO GARCIA, Arturo, Iglesia e Ilustración, pp. 79-80.

${ }^{69}$ Erección de la Congregación de feligreses para la Hospitalidad Doméstica, Cádiz, s.a. Bibliateca de Temas Gaditanos.

"Archivo Diocesano de Cádiz, Secretaria, edictos impreso, numero 103, y legajo 50; Inversión de donativos en beneficio público por el obispo de la citudad, Cádiz, s.a., Biblioteca de Temas Gaditanos.
} 
Estas iniciativas fueron bastante bien acogidas por amplios sectores de la Iglesia gaditana, $y$, de hecho, José Ruiz y Román, en la oración fúnebre dedicada a Martínez de la Plaza con motivo de su fallecimiento, mostraba cómo "estaba reservado a este dulce Antonio el arbitrio más sabio de la beneficencia, el de la caridad afable aún a los mismos pobres...Habite la enfermedad donde quiera: en el oscuro albergue de la indigencia allí esta el Obispo visitando, asistiendo, consolando, socorriendo, curando"70. Los elogios del panegirista estaban claramente justificados, por cuanto los desvelos del prelado permitían a la Iglesia estar presente en primera línea en la organización de la beneficencia, recuperando una iniciativa que el Hospicio debió haber, en bastante medida, ensombrecido. Pero parece que el conjunto de la sociedad gaditana $(0$, al menos, sus élites económicas) respiraba otros aires: entre 1793 y 1807 la Hospitalidad Domestica recogió un total de 1.603 .000 reales en calidad de limosnas ${ }^{71}$, pero las sumas percibidas por el Hospicio por dicho concepto ascendieron a 3.668.00072, y tan sólo en 1800, año de la fiebre amarilla, la proporción se invirtió a favor de la primera. Todo ello nos puede indicar que los grupos más favorecidos de la sociedad gadicense (que, en definitiva, eran quienes proporcionaban mayor cantidad de limosnas) eran más partidarios de un concepto laico, carcelario y productivista de la beneficencia, que de los viejos marcos de asistencia domiciliaria en la cual la Iglesia seguía jugando un importante papel. El triunfo del régimen liberal daría a la primera de ambas opciones el espaldarazo definitivo.

${ }^{77}$ Cit. por ANTÓN SOLE, Pablo, La Yglesia, p. 197.

"La Hospitalidad Doméstica.

${ }^{72}$ Archivo General de la Diputación de Cádiz, Libros de Actas de la Junta Directiva del Hospicio, 507 516. 